\title{
Measuring Empathy Towards Patients among Dental Under Graduate Students of Bangalore City-A Cross Sectional Study
}

\author{
Gouthami Datta, Vanishree N, Sushma S Nayak, Deepa Bullappa, Naveen N, Ramesh Lakshmikantha, Keerthi \\ Prasad K.S, Anushri M.
}

\section{Gouthami Datta, Vanishree N, Sushma S Nayak, Deepa Bullappa, Naveen N, Ramesh laksh- mikantha, Keerthi Prasad K.S, Anushri M.}

Department of Public Health Dentistry, Bangalore Institute of Dental Sciences, Bangalore, INDIA.

\section{Correspondence}

Dr. Deepa Bullappa, Senior Lecturer, Department of Public Health Dentistry, Bangalore Institute of Dental Sciences, Bangalore, INDIA.

Email: deepabullappa@gmail.com

\section{History}

- Submission Date: 03-09-15:

- Review completed: 18-06-16;

- Accepted Date: 22-06-16.

DOI : 10.5530/ijmedph.2016.3.3

Article Available online

http://www.ijmedph.org/v6/i3

\section{Copyright}

(c) 2016 Phcog.Net. This is an openaccess article distributed under the terms of the Creative Commons Attribution 4.0 International license.

\begin{abstract}
Background: Researchers have described empathy as a cognitive attribute, which means it predominantly involves understanding another person's concerns. It has also been described as an affective or emotional characteristic, which implies that it primarily involves feeling another person's pain and suffering. Because empathic patient interactions by dentists are associated with improved patient outcomes, self-reported declines in empathy during dental student training are a concern.
\end{abstract}

Aim: To measure empathy levels among $3^{\text {rd }}$ year, $4^{\text {th }}$ year undergraduate students and interns studying in dental colleges of Bangalore city and to investigate the differences in empathy scores based on gender and year of dental training.

Methodology: A cross sectional descriptive research was undertaken among 800 dental students ( $3^{\text {rd }}$ year, final year and interns) to measure the empathy levels using Jefferson Scale of Physician Empathy-Health Professionals Version (JSPE-HP) questionnaire containing 20 items answered on a 5-point Likert scale (strongly agree, agree, neutral, disagree and strongly agree). The data was analyzed using SPSS 21.

Results: Out of $800(100 \%)$ dental students, 300 (37.5\%) were males and 500 (62.5\%) were females with the mean age of males and females $22.93 \pm 1.72$ and $21.87 \pm 1.28$ respectively. The mean empathy scores with respect to age was more for 21-22 yrs whereas based on gender, empathy scores were more for males and there was not much difference found with the empathy scores with respect to fourth year students and interns.

Conclusion: This cross-sectional study explored differences in empathy among dental student groups in the context of existing evidence that empathy declines as students progress through dental course.

Key words: Dental, Empathy, Patients, Students, Under-graduates.

\section{INTRODUCTION}

Professionalism encompasses the appropriate attitudes, values and behaviours needed for a practicing dentist. The most important attributes for professionalism, as determined by health professionals, are competence, respect and empathy. ${ }^{1}$ Empathy itself, however, is a difficult and complex concept to define. It can be considered a state, trait or 'multistage interpersonal process.'2

Researchers have described empathy as a cognitive attribute, which means it predominantly involves understanding another person's concerns. Another group of researchers have viewed empathy as both affective and cognitive, whereas in health care field it has been linked to ideas of compassion, thoughtfulness, attentiveness, and caring attitude. These culminate into a desirable type of "chair side manner" that generates understanding and produces positive rapport with patients. ${ }^{2-4}$

One of the challenges in measuring empathy among health care professionals is the abundant descriptions of empathy from the various domains of psychology and neuroscience. Although many formal descriptions of empathy exist, a concise agreed-upon definition of empathy is still lacking. ${ }^{5}$

Medical research has shown that the use of a "warm, empathic style" by physicians during communications with patients is associated with improved treatment outcomes such as increased compliance with medical recommendations, decreased pain, and reduced recovery time, as well as increased patient satisfaction and decreased medical litigation. The literature in dentistry reflects similar trends as those noted in medical practice. Specifically, the demonstration of empathy by dentists has been correlated with decreased dental fear, increased compliance with orthodontic treatment, improved treatment success and cooperation in pediatric patients, improved treatment outcomes in myofacial pain, and increased patient satisfaction. . $^{6,7}$

There are numerous methods to assess empathy: self-ratings, patient ratings, peer ratings, psychometric tests and observation of behaviours, all of
Cite this article : Datta G, Vanishree N, Nayak SS, Bullappa D, Naveen N, Lakshmikantha R, Prasad KS, Anushri M. Measuring Empathy Towards Patients among Dental Under Graduate Students Of Bangalore City-A Cross Sectional Study. J. Med. Public Health, 2016; 6(3):113-6. 
which have their advantages and disadvantages. Among these, the Jefferson scale of physician empathy has been found to be valid and reliable in assessing empathy among dental students. ${ }^{2,3,8,9}$

Most of the studies reveal that there is a decrease in empathy as the students progress in their academics. However there are very few studies assessing empathy among dental students. In dentistry, for Under Graduate students, patient exposure happens only at the third year entry level. No study has been conducted among dental students in India, hence the present study was planned with an aim of assessing empathy levels among $3^{\text {rd }}$ year, $4^{\text {th }}$ year undergraduate students and interns of Bangalore city with objectives-to measure empathy levels among undergraduate students and interns studying in dental colleges of Bangalore city and to investigate the differences in empathy scores based on gender and year of dental training.

\section{METHODOLOGY}

A cross sectional descriptive research was undertaken in July to August 2013. The target population included $3^{\text {rd }}$, final year and internship students studying in Dental colleges of Bangalore city. List of the Dental colleges and number of students enrolled in Bangalore city were obtained from Rajiv Gandhi University of Health Sciences. www.rguhs.ac.in. ${ }^{10}$

A total of 16 dental colleges (1 Government and 15 Private) are there in Bangalore city which are affiliated to Rajiv Gandhi University of Health and Sciences, having approximately 3000 dental students belonging to $3^{\text {rd }}, 4^{\text {th }}$ year and internship during the tenure of this study. Out of 16 dental colleges, 9 dental colleges gave permission for conducting the study which comprised to 800 students.

Ethical Committee approval was obtained from the Institution Ethics Committee. Prior permission was obtained from the Head of the Institutions of the respective Dental colleges selected for conducting this study. Informed consent was obtained from the participants. In dentistry, for Under Graduate students, patient exposure happens only at the third year entry level, so Under Graduate students studying in $3^{\text {rd }} \mathrm{yr}$, final yr and doing rotatory internship and were present on the day of study were included in the study.

A pilot study was conducted among 50 dental students to assess the comprehension of the questionnaire. Based on this, necessary modifications were done in the questionnaire which was later validated. The subjects of each college were made to assemble in a hall and the purpose of the study was described to them. The subjects were told to provide accurate answers and anonymity of response was assured. The subjects were given 30 minutes time to complete the self administered questionnaires. The questionnaires were later collected back. Data was coded and analyzed.

\section{Data Collection Tool}

With regard to empathy being independent variable, age of the students, gender and year of the study were taken as independent variables. The survey instrument consists of Jefferson Scale of Physician EmpathyHealth Professionals Version (JSPE-HP) questionnaire containing 20 items answered on a 5-point Likert scale (strongly agree, agree, neutral , disagree and strongly agree). To control for "acquiescence" response style 10 items are positively worded and 10 items are negatively worded. The original questionnaire consisted of a 7 point Likert scale which was then modified to a 5 point Likert scale in the present study. ${ }^{11}$

The questionnaire consisted of two parts:

a. Four questions pertaining to the respondents' demographic details(name, age, gender, year of study).

b. The second section of the questionnaire consisted 20 items to assess the levels of empathy.

\section{Statistical Analysis}

The data collected was entered into the computer (MS-Office, Excel 2007) and subjected to statistical analysis using the statistical packageSPSS version 21. Descriptive statistics with frequency, percentage, mean and standard deviation were taken. Statistical significance was considered at $p<0.05$ (confidence interval of 95\%). Unpaired t test, Mann Whitney $U$ test and ANOVA were used to assess the difference in empathy levels among the students in relation to gender and year of study.

\section{RESULTS}

Out of 800 (100\%) dental students, 300 (37.5\%) were males and 500 (62.5\%) were females with the mean age of males and females $22.93 \pm 1.72$ and $21.87 \pm 1.28$ respectively. Majority $(49.75 \%)$ were in the age group of 21-22 years followed by 23-24 yrs-(34.13\%); 19-20 yrs-(9.25\%). Among them, $232(29 \%)$ were in third year followed by $270(33.75 \%)$ in final year and 298 (37.25\%) were interns (Table 1).

The mean empathy scores with respect to age was more in the 21-22 yrs i.e., $70.54 \pm 9.43$ followed by $23-24$ years i.e., $70.19 \pm 9.23$. There was a Significant difference found in mean empathy scores between 19-20 yrs and 21-22 yrs ( $p=0.03$ ) (Table 2). Based on gender, empathy scores were more for males $(70.95 \pm 69.48)$ (Table 3$)$. With regard to comparison of the mean score of empathy with respect to year of study, significant difference was found between third year students $(71.71 \pm 99)$ and final year students $(69.36 \pm 9.08)(p=0.012)$ and also between third year students $(71.71 \pm 99)$ and interns $(69.33 \pm 8.54)(p=0.008)$ (Table 4).

\section{DISCUSSION}

The present study assessed the empathy levels among third year students, final year students and interns attached to dental colleges of Bangalore city. Empathy was taken as the topic of present study as it forms the backbone of doctor patient relationship and hence is very important quality that a health professional should possess.

According to Kulich et al, empathetic communication appears to be a particularly important, but under-provisioned in dental education. ${ }^{12}$ In the present study, three batches of students $\left(3^{\text {rd }}\right.$, final, interns) were considered because these students come in contact with patients which is contrary to the study by A. Beattie ${ }^{2}$ where only first year students were part of study. In this study, the mean empathy score was more in the age group of 21-22 years (70.54) and for males (70.95) where as the mean score was 61.88 in pre-course in A. Beattie study but there was no statistical significant difference found.

The empathy scores were more in third year as compared to final year students and interns which shows that lack of training or education related to empathy in dental college will lead to the decline in empathy scores gradually. Empathy scores are more in the third year as it is the first time contact with patients. In line with our results, Sherman and Cramer found that empathy levels decreased in the second year of dental school, which in their cohort correlated with first patient contact. ${ }^{13}$ Empathy can be 'taught' by lectures, role-playing and interviewing skills, but what Hafferty describes as the informal curriculum can also have a significant impact. ${ }^{14}$

Given the importance of empathy to the dentist-patient relationship, one may ask whether empathy can be increased through training. Whilst some authors have found that dental and other health professional students can be taught methods to increase empathy ${ }^{2}$ others have found that increases may be short-lived ${ }^{15,16}$ Still others have argued that empathy cannot be taught. ${ }^{17}$ Even then empathy should be considered an important element in patient care and a significant factor of overall physician competence that must be enhanced during dental education, and applied in the practice of dentistry. 
Table 1: Distribution of the study subjects based on age and year of study

\begin{tabular}{cccccc}
\hline \multirow{2}{*}{ AGE GROUPS } & AGE & Male & $\begin{array}{c}\text { Females } \\
\text { N (\%) }\end{array}$ & $\begin{array}{c}\text { Total } \\
\text { N (\%) }\end{array}$ & $\begin{array}{c}\text { Chi-square }=112.86 \\
\text { p-value- } 0.00^{* * *}\end{array}$ \\
\hline & $19-20$ yrs & $18(24.32)$ & $56(75.68)$ & $74(9.25)$ & \\
& $21-22$ yrs & $97(24.37)$ & $301(75.63)$ & $398(49.75)$ & \\
$23-24$ yrs & $137(50.18)$ & $136(49.82)$ & $273(34.13)$ & \\
& $25-26$ yrs & $40(90.91)$ & $4(9.09)$ & $44(5.50)$ & \\
& $27+$ yrs & $8(72.73)$ & $3(27.27)$ & $11(1.38)$ & \\
& Third year & $63(27.16)$ & $169(72.84)$ & $232(29)$ & \\
& Final Year & $90(33.33)$ & $180(66.67)$ & $270(33.75)$ & Chi-square $=30.38$ \\
& Interns & $147(49.33)$ & $151(50.67)$ & $298(37.25)$ & p-value- $0.00^{* *}$ \\
& Total & $300(37.5)$ & $500(62.5)$ & $800(100)$ & \\
\hline
\end{tabular}

**- Highly Significant.

Table 2: Comparison of mean empathy scores based on age

\begin{tabular}{ccccccc}
\hline Age groups & $19-20$ yrs & 21-22 yrs & 23-24 yrs & 25-26 yrs & 27+yrs & ANOVA \\
\hline Mean & $67.16^{\mathrm{a}}$ & 70.54 & 70.19 & 69.84 & 67.55 & $F$ - value- 2.34 \\
S.D & 9.15 & 9.43 & 9.23 & 6.54 & 8.10 & $p$ - value- 0.05 \\
\hline
\end{tabular}

$\mathrm{a}=$ Significant difference between 19-20 yrs and 21-22 yrs $(p=0.03)$

(Tukeys multiple post hoc).

Table 3: Comparison of mean empathy scores based on gender

\begin{tabular}{cccc}
\hline Gender & Males & Females & \\
\hline Mean & 70.95 & 69.48 & ' $t$ ' value- 2.2 \\
S.D & 9.22 & 9.18 & $p$-value- $0.02^{*}$ \\
\hline
\end{tabular}

Table 4: Comparison of mean empathy scores based on the year of study

\begin{tabular}{ccccc}
\hline Year of study & Third year & Final year & Interns & ANOVA \\
\hline Mean & 71.71 & $69.36^{\mathrm{a}}$ & $69.33^{\mathrm{b}}$ & F- value-5.49 \\
S.D & 9.99 & 9.08 & 8.54 & $p$ - value- 0.004 \\
\hline
\end{tabular}

$\mathrm{a}=$ Significant difference between third year and final year students $(p=0.012)$

$\mathrm{b}=$ Significant difference between third year students and interns $(p=0.008)$

(Tukeys multiple post hoc).

Limitations of the study are: comparisons were performed between different groups of students. The scores would have been more comparable had the same population been followed from $3^{\text {rd }}$ year till they became interns. Socio-economic status was not considered due to the reasons that $15 \%$ students were NRI, previous dental experiences were not considered in the analysis. This would have had an impact on their empathy scores.

In conclusion, this cross-sectional study explored differences in empathy among dental students in the context of existing evidence that empathy declines as students progress through dental course. Observational studies to investigate dental students' attitudes, and the function of both teaching and role models in the formation of these attitudes, warrant further research.

\section{CONCLUSION}

In conclusion, this cross-sectional study explored differences in empathy among dental students in the context of existing evidence that empathy declines as students progress through dental course. Observational studies to investigate dental students' attitudes, and the function of both teaching and role models in the formation of these attitudes, warrant further research. 


\section{ACKNOWLEDGEMENT}

A special thanks to all the dental students for their kind co-operation. Funding: This is an ICMR(Indian Council of Medical Research) approved project (Short Term Studentship-STS) with reference id-2013-03770.

\section{CONFLICT OF INTEREST}

Authors declare no conflict of interest.

\section{ABBREVIATION USED}

Abbreviations are elaborated as and when they appear in the article.

\section{REFERENCES}

1. Brownell $A K$, Côté $L$. Senior residents' views on the meaning of professionalism and how they learn about it. Acad Med. 2001;76(7):734-7. http://dx.doi. org/10.1097/00001888-200107000-00019 PMid:11448832

2. Muneer GB. Empathy heals: Learn to walk a mile in their shoes. IeJSME. 2011:5(2):1-2.

3. Beattie A, Durham1 J, Harvey J, Steele J, McHanwell S. Does empathy change in first-year dental students? Eur J Dent Educ. 16 (2012) e111-e116. http:// dx.doi.org/10.1111/j.1600-0579.2011.00683.x ; PMid:22251333

4. Yarascavitch $C$ et al. Changes in Dental Student Empathy During Training. Journal of Dental Education. 2009;73(4); 509-18 PMid:19339438

5. Hojat M et al. Physician Empathy: Definition, Components, Measurement, and Relationship to Gender and Specialty. Am J Psychiatry. 2002;159:1563-15 http:// dx.doi.org/10.1176/appi.ajp.159.9.1563 ; PMid:12202278

6. Hojat M, Gonnella JS, Nasca TJ, Mangione S, Veloski JJ, Magee M. The Jefferson Scale of Physician Empathy: further psychometric data and differences by gender and speciality at item level. Acad Med. 2002:77(Suppl.): S58-S60. http://dx.doi.org/10.1097/00001888-200210001-00019 ; PMid:12377706
7. Sherman JJ, Cramer A. Measurement of changes in empathy during dental school. J Dent Educ. 2005;69(3):338-45. PMid:15749944

8. Hemmerdinger J, Stoddart S, Lilford R. A systematic review of test of empathy in medicine. BMC Med Educ. 2007:7:24-9. http://dx.doi.org/10.1186/1472-69207-24 : PMid:17651477 PMCid:PMC1988794

9. Hojat M, Gonnella JS, Mangione S, et al. Empathy in medical students as related to clinical competence, gender, and academic performance. Med Educ. 2002:36:522-7. http://dx.doi.org/10.1046/j.1365-2923.2002.01234.x; PMid:12047665

10. List of Dental colleges issued notification for the year 2007-08 subject to the condition (online). 2015. [cited on 25 $5^{\text {th }}$ feb, 2015]; Available from www.rguhs. ac.in.

11. Kataoka H, Koide N, Ochi K, Hojat M, Gonnella JS. Measurement of empathy among Japanese medical students: Psychometrics and score differences by gender and level of medical education. Acad Med. 2009;84:1192-1197. http:// dx.doi.org/10.1097/ACM.0b013e3181b180d4; PMid:19707056

12. Karydis A, Komboli-Kodovazeniti M, Hatzigeorgiou D, Panis V. Expectations and perceptions of Greek patients regarding the quality of dental health care. Int J Qual Health Care. 2001;13(5):409-16. http://dx.doi.org/10.1093/intqhc/13.5.409; PMid:11669569

13. Jones LM, Huggins TJ. Empathy in the dentist-patient relationship: review and application. N Z Dent J. 2014;110 (3):98-104. PMid:25265748

14. Del Canale S, Louis DZ, Maio V, Wang X, Rossi G, Hojat M, et al. The Relationship Between Physician Empathy and Disease Complications: An Empirical Study of Primary Care Physicians and Their Diabetic Patients in Parma, Italy. Acad Med. 2012;87(9):1243-9. http://dx.doi.org/10.1097/ACM.0b013e3182628fbf; PMid:22836852

15. Hafferty FW. Beyond curriculum reform: confronting medicine's hidden curriculum. Acad Med. 1998:73:403-7. http://dx.doi.org/10.1097/00001888-19980400000013 ; PMid:9580717

16. Van Winkle LJ, Fjortoft N, Hojat M. Impact of a workshop about aging on the empathy scores of pharmacy and medical students. Am J Pharm Educ. 2012:76(1):9. http://dx.doi.org/10.5688/ajpe7619; PMid:22412208 PMCid:PMC3298407

17. Davis CM. What is empathy, and can empathy be taught?. Phys Ther 1990:70:32-6

Cite this article : Datta G, Vanishree N, Nayak SS, Bullappa D, Naveen N, Lakshmikantha R, Prasad KS, Anushri M. Measuring Empathy Towards Patients among Dental Under Graduate Students Of Bangalore City-A Cross Sectional Study. J. Med. Public Health, 2016; 6(3):113-6. 